\title{
Free Solution Assay Signal Modulation in Variable-Stem-Length Hairpin Aptamers
}

Michael N. Kammer ${ }^{1}$, Amanda K. Kussrow ${ }^{1}$, Ian R. Olmsted ${ }^{1}$, George W. Jackson ${ }^{2}$ and Darryl J. Bornhop ${ }^{{ }^{*}}$

1. Vanderbilt Department of Chemistry; 2. Base Pair Biotechnologies, Inc. Pearland, TX 77584

*Corresponding author

Saturation isotherms performed as described in the main text.

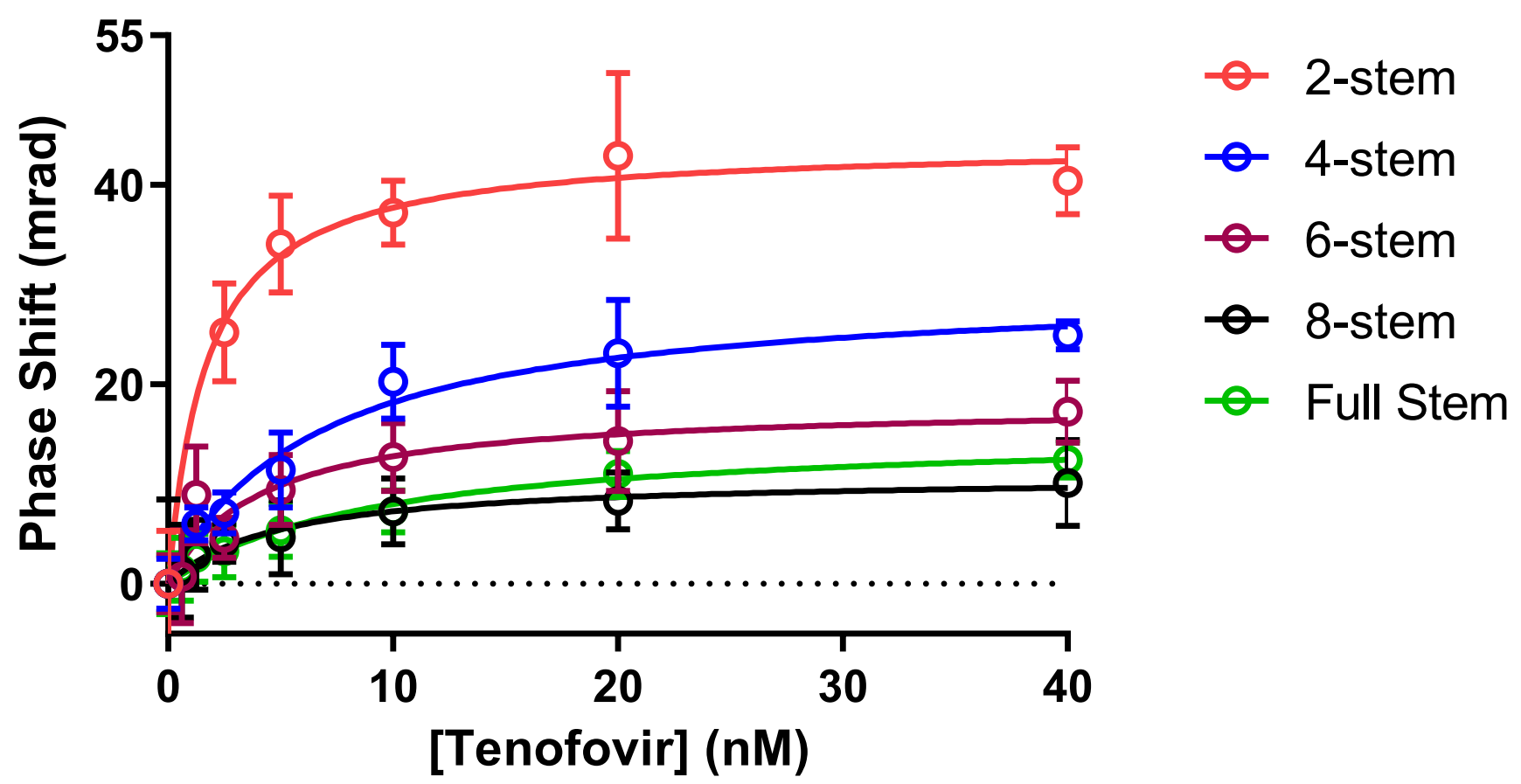

Figure S1: Saturation isotherms of the 5 hairpins. Error bars denote SEM of 3 determinations. 